\title{
Uso correcto del español en la redacción de artículos biológicos
}

\author{
Julián Monge-Nájera ${ }^{1}$ \& Silvia Méndez Anchía ${ }^{2}$ \\ 1. Biología Tropical, Universidad de Costa Rica, 2060 San José, Costa Rica; rbt@cariari.ucr.ac.cr \\ 2. Programa de Producción de Material Impreso, Universidad Estatal a Distancia, 47-2050 San José, Costa Rica; \\ smendez@uned.ac.cr
}

\begin{abstract}
Correct use of Spanish when writing biological papers. We present a list of the most frequent errors in biological manuscripts written in Spanish, and we explain which are the recommended options. Our article is based on the International Codes of Nomenclature, and the guidelines of the Real Academia de la Lengua and the Council of Science Editors. We group the indications in four categories: lexical errors (e.g. English cognates); spelling (graphic accents, punctuation, font), morphology (use of prepositions) and style (linguistic economy). Rev. Biol. Trop. 56 (4): 1589-1593. Epub 2008 December 12.
\end{abstract}

Key words: writing in Spanish, correct use of the Spanish language, biology, science, bad translations, technical writing.

En biología, cerca de un $90 \%$ de los artículos se publican en inglés, mientras que los artículos en español no llegan al $1 \%$ (MongeNájera y Nielsen 2005). Sin embargo, muchos autores iberoamericanos publican en español. En el caso de la biología neotropical, se ha mencionado, como criterio a favor de escribir en español, el uso de este idioma en América Latina. Esto se ha rebatido argumentando que el español no es leído por la vasta mayoría del personal científico mundial, aislándose con ello a la ciencia latinoamericana y reduciendo enormemente su impacto (Monge-Nájera 2002). El fenómeno no es nuevo; hacia el final de su vida, Santiago Ramón y Cajal afirmó: "los científicos no quieren leer el español. Casi cada semana sé de publicaciones alemanas o estadounidenses donde otras personas vuelven a descubrir lo que yo observé hace años" (Berbell 1999).

Independientemente de este debate, este artículo aclara el uso del español en la redacción sobre temas biológicos, con base en los errores y dudas más frecuentes que se han detectado por más de 20 años en los manuscritos recibidos en la Revista de Biología Tropical y otras revistas en que el primer autor ha sido editor o revisor.

En el caso de los errores, explicamos cuáles son las palabras correctas. Cuando son correctas varias formas, explicamos cuál es la recomendada. Como autoridad usamos, para aspectos concretos del español, las recomendaciones de la Real Academia Española y, para otros problemas de redacción científica, las normas del Council of Science Editors. Agrupamos las correcciones y recomendaciones en cuatro categorías: léxico (e.g. anglicismos), ortografía (acentuación gráfica, puntuación, mayúsculas), morfología (uso de preposiciones) y estilo (economía lingüística).

\section{Léxico (influencia de otros idiomas)}

En general, los problemas de léxico reflejan la importancia del inglés dentro del campo biológico. Así como en el pasado la influencia del francés llevaba a algunas personas a usar "protozoario" (del francés, protozoire) en lugar 
de la expresión española correcta protozoo, hoy son comunes los anglicismos innecesarios. Advertimos que en este artículo no entraremos en el debate sobre si es mejor olvidarnos de la corrección y usar una palabra incorrecta, pero ampliamente usada y comprendida. Estamos de acuerdo en que lo más importante en la comunicación es darse a entender, pero cuando existen en español formas aceptadas, estas formas son estables y universales (basta con consultar el diccionario de la Real Academia Española, impreso o en la dirección electrónica www.rae.es).

Para cada caso se presenta la forma incorrecta o no recomendada como un subtítulo, para facilitar la consulta. Todos los ejemplos son ficticios.

\section{FORMAS INCORRECTAS}

\section{Colecta, colectar}

Del inglés collect. En español: "recolectar", "recoger", "recolección", "recolector", etc. En cambio, sí es correcto referirse a una colección de especímenes. Ejemplo: Recolectamos (recogimos) los especímenes con una red de mano y los depositamos en la colección institucional.

\section{La genitalia}

"La genitalia" es incorrecto. Ha estado en uso por influencia de los textos en inglés, ya que este término latino fue adoptado en la lengua inglesa pasando a formar parte de ella, en donde la "a" final no indica género, sino número (plural). Al usarlo en español tal cual se cometen dos errores: interpretarlo como un sustantivo femenino por la "a" final y como un sustantivo en singular por la falta de una "s" al final, lo que explica el uso del artículo "la", que indica género femenino y número singular. Lo correcto por "la genitalia", entonces, es "los órganos genitales".

\section{La taxa}

Presenta el mismo error de "la genitalia" y "la multimedia", proveniente del inglés: the taxa, adoptado del latín. En español, el Código Internacional de Nomenclatura (AlonsoZarazaga 2004) indica que las traducciones oficiales son "el taxon" (singular) y "los táxones" (plural).

\section{Ocurre, ocurrencia}

En expresiones como "esta especie ocurre en el Mar Caribe" o "la ocurrencia de esta especie en ese hábitat requiere una explicación", se está calcando el inglés occur. Lo correcto en español es usar "habita", "se encuentra", "se da" y "está presente". Ejemplos: "esta especie habita (se encuentra, se da, está presente) en el Mar Caribe" o "la presencia de esta especie en ese hábitat requiere una explicación".

\section{Sobrevivencia}

Confusión entre sujeto y hecho. Lo correcto en español es supervivencia (no confundir con sobreviviente). Ejemplo: "Es notable la supervivencia de esta especie a la extinción del Jurásico".

\section{Rango}

Del inglés range. Lo correcto en español es ámbito, gama o escala, según el caso. Ejemplos: "el ámbito de esta especie es desde México hasta Brasil"; "este parásito tiene un amplio ámbito de hospederos", "en esta escala de valores", "en esta gama de colores". "Rango" es correcto para referirse a jerarquías: "en taxonomía, la familia tiene un rango superior al género".

\section{Vial}

Del inglés vial. En español, simplemente "frasco". 


\section{Ripario}

Del inglés ripary, significa "ribereño" en español; el uso de esta traducción causa confusión en trabajos ecológicos y botánicos.

\section{Juvenil}

Tomado del inglés juvenile, aparece en frases como "los juveniles emigran mar adentro". Lo correcto en el sustantivo es "joven": "los jóvenes emigran mar adentro" ("juvenil" es un adjetivo). Lo incorrecto es utilizar "juvenil" como sustantivo.

Las siguientes palabras no son recomendadas, pero la Real Academia menciona que se usan con frecuencia.

\section{Reportar, reporte y rol}

Todas aceptadas en su uso científico por la Real Academia Española: del inglés report y role. Son versiones más castizas "informar", "informe" y "papel".

\section{ERRORES DE ORTOGRAFÍA}

Recomendamos el uso del corrector ortográfico de su procesador de textos. Aun así, la frecuencia con que se reciben manuscritos con estos errores justifica su inclusión.

\section{Fué, vió, dió}

Aunque estas palabras monosílabas dejaron de tildarse desde mediados del siglo anterior, persiste la costumbre de tildarlas. Lo correcto es "fue", "vio" y "dio".

\section{Más}

"Más" se tilda cuando es adverbio de cantidad ("más derivado evolutivamente").

\section{Aún}

"Aún" se tilda cuando equivale a "todavía" ("aún se encontró esa población"), pero no se tilda cuando puede sustituirse por "incluso" ("todos los individuos estaban parasitados, aun los que no habían sido inoculados experimentalmente").

\section{Títulos De Tipo Anglosajón}

En español no se inician con mayúscula todas las palabras de los títulos y subtítulos; únicamente la primera palabra y los nombres propios. Incorrecto: "Ciclos Reproductivos de las Algas Macrófitas del Refugio Nacional Matambú, Caribe Colombiano". Correcto: "Ciclos reproductivos de las algas macrófitas del Refugio Nacional Matambú, Caribe colombiano".

\section{MORFOLOGÍA (USO DE PREPOSICIONES, ADVERBIOS Y GERUNDIOS)}

Estos también son errores básicos de redacción: su inclusión en este artículo se justifica por la frecuencia con que aparecen en los manuscritos.

\section{Alrededor del año, alrededor del mundo}

Tomadas del inglés (e.g. the year round, around the world), en estas frases es mejor traducir "around" como "todo": "la especie se encuentra aquí todo el año" o "en todo el mundo".

\section{En el largo plazo, en el corto plazo}

Del inglés in the long run, in the short run. En español: a largo plazo, a corto plazo.

\section{Bajo condiciones}

Lo correcto es "en condiciones". Ejemplo: "Antes de la biopsia, los organismos se mantuvieron en condiciones de laboratorio al menos durante 30 días".

\section{Bajo diferentes concentraciones}

Lo correcto es "en diferentes concentraciones". Ejemplo: "El extracto en etanol se probó en diferentes concentraciones con ratas normales". 


\section{Bajo diversas circunstancias}

Lo correcto es "en diversas circunstancias". Ejemplo: "El mono colorado (Ateles geoffroyi) es un primate diurno que forma manadas en diversas circunstancias".

\section{Mostrando}

Es común, en los pies de figura, escribir algo semejante a "Análisis de componentes principales mostrando los factores que definen la morfología de la especie". En estos casos, "mostrando" es un gerundio indebidamente usado. Se recomienda no usar esos gerundios (como "conteniendo" y "mostrando"). Ejemplo de forma mejorada: "Análisis de componentes principales con los factores que definen la morfología de la especie".

\section{ESTILO CIENTÍFICO (ECONOMÍA LINGÜÍSTICA)}

Actualmente se evita la redacción pasiva. El uso de la primera persona se recomienda tanto para el texto principal como para los resúmenes. Ejemplo de redacción pasiva: "La cantidad de individuos fue medida". Forma recomendada: "Medimos la cantidad de individuos".

Una norma básica de la redacción científica, recogida por el Council of Science Editors (2006), es evitar las repeticiones. Ya en el siglo XVIII, Linneo había reconocido que el estilo conciso hacía más inteligibles las descripciones taxonómicas. Sin llegar al estilo telegráfico, el resto de la redacción científica debe tener economía lingüística, por dos grandes razones: la redacción sin redundancia resulta más comprensible y ahorra tiempo.

\section{En el mes de, en los meses de}

Es inútil escribir, por ejemplo, "la especie florece en los meses de mayo y junio", cuando basta "la especie florece en mayo y junio" (además, en español los nombres de los meses se escriben con minúscula, no "Mayo" o "Junio").

\section{Mapa; fotografía de microscopio electrónico; gráfico de barras}

Es innecesario escribir lo obvio. Si podemos leer un artículo científico, podemos reconocer un mapa, una fotografía o un histograma. En lugar de "Mapa de los lugares de muestreo", basta "Lugares de muestreo".

\section{Resultados obtenidos}

Este es otro ejemplo común de palabras innecesarias. Ejemplo: "Los resultados obtenidos muestran que la fenología de esta especie varía considerablemente". Casi siempre la oración mantiene su sentido si escribimos simplemente "resultados". Ejemplo: "Los resultados muestran que la fenología de esta especie varía considerablemente".

Esperamos que este artículo ayude a valorar el español utilizado en textos sobre biología y sirva tanto en la elaboración de manuscritos como en la docencia, pues la mayoría del estudiantado latinoamericano no recibe suficiente formación en este campo fundamental para su labor de investigación.

\section{AGRADECIMIENTO}

Agradecemos la revisión crítica de César Lodeiros, Orlando García Valverde y dos revisores anónimos, cuyos comentarios permitieron mejorar el manuscrito.

\section{RESUMEN}

Presentamos una lista de los errores más comunes en los manuscritos biológicos redactados en lengua española, explicando cuáles son las palabras recomendadas. Nos basamos en las recomendaciones de la Real Academia Española y los Códigos Internacionales de Nomenclatura, así como en las normas del Consejo de Editores Científicos. Agrupamos las correcciones y recomendaciones en cuatro categorías: léxico (e.g. anglicismos), ortografía (acentuación gráfica, puntuación, mayúsculas), morfología (régimen preposicional) y estilo (economía lingüística).

Palabras clave: redacción castellana, uso correcto del español, biología, ciencia, anglicismos, redacción técnica. 


\section{REFERENCIAS}

Alonso-Zarazaga, M.A. (traductor). 2004. Código Internacional de Nomenclatura Zoológica. Sociedad de Amigos del Museo Nacional de Ciencias Naturales, Madrid.

Berbell, C. 1999. Santiago Ramón y Cajal. Rueda, Madrid.

Council of Science Editors. 2006. Scientific Style and Format. The CSE Manual for Authors, Editors, and Publishers. Council of Science Editors, Reston, Virginia, EEUU. 680 p.
Monge-Nájera, J. \& V. Nielsen 2005. The countries and languages that dominate biological research at the beginning of the 21 st century. Rev. Biol. Trop. 53: 283-294.

Monge-Nájera, J. 2002. Cómo hacer ciencia en los trópicos. Rev. Biol. Trop. 50: xxiv-xxviii.

Real Academia de la Lengua. 1999. Ortografía de la lengua española. Espasa-Calpe, Madrid.

Real Academia de la Lengua. 2001. Diccionario de la lengua española. Espasa-Calpe, Madrid.

Recibido 13-III-2007. Corregido 18-X-2007. Aceptado 29-X-2008.

Editado por Bernal Morera 
